\title{
Differential Effects of Selected Psychotherapeutic Interventions on Procrastination Reduction and Improved Mathematics Achievement among Low Achieving Students
}

\author{
Ugwueze Stella ${ }^{1, *}$, Agbakwuru Chikwe², Ekeh P. $\mathrm{U}^{2}$ \\ ${ }^{1}$ Department of Psychology, College of Management and Social Sciences, Renaissance University Ugbawka Enugu, Enugu State \\ ${ }^{2}$ Department of Educational Psychology, Guidance and Counselling, Faculty of Education, University of Port Harcourt, Nigeria \\ *Corresponding author: stellaug@gmail.com
}

\begin{abstract}
This study investigated the differential effects of selected psychotherapeutic interventions on procrastination reduction and improved mathematics achievement among low achieving students in Enugu State. Quasi-experimental, Pre-test, post-test, control group, research design was adopted. A purposive sampling was used to select a sample of $n=36$ Senior Secondary School One (SS1) students both male and female. Participants were randomly assigned to three groups "A," "B" and "C". Cognitive-Behaviour Therapy (CBT) and Solution-Focused Brief Therapy (SFBT) interventions were used for the study. The treatment with CBT was applied to group "A" for 15 weeks while SFBT was applied to group "B" for 8 weeks. The instruments used include, Procrastination Assessment Scale-Students (PASS), Teacher Made Mathematics Diagnostic Test (TMMDT) and Teacher Made Mathematics Achievement Test (TMMAT). They were validated and reliability tested. Their correlation scores were, $.900, .816$ and .868 for the three instruments respectively. The ANCOVA result shows that $F(2,32)=33.44$, $\mathrm{p}=001$ and a differential effects of CBT and SFBT between groups. The result showed that SFBT had more effects on procrastination reduction and also a significant difference in mathematics improvement of the students in CBT and SFBT experimental groups from pre-test and post-test scores, is rejected both at .05 and .01 levels of significance. From the study we conclude that CBT and SFBT interventions are effective on procrastination reduction and improved mathematics achievement among low achieving student but there is no gender effect. We recommend that psychotherapeutic interventions should be used to improve academic achievement in general.
\end{abstract}

Keywords: psychotherapy, CBT, SFBT, procrastination, achieving

Cite This Article: Ugwueze Stella, Agbakwuru Chikwe, and Ekeh P. U, "Differential Effects of Selected Psychotherapeutic Interventions on Procrastination Reduction and Improved Mathematics Achievement among Low Achieving Students." American Journal of Educational Research, vol. 6, no. 4 (2018): 354-360. doi: 10.12691/education-6-4-9.

\section{Introduction}

Low academic achievements of students in secondary schools today makes one to look at behaviours they exhibit that are dysfunctional in nature, so as to proffer solution. So many individuals have tried to identify these sabotaging behaviours. The Commissioner for Education in Enugu State, Nigeria, attributed the mass failure to poor reading culture by students as so many of them engage in examination malpractice [1]. While some stakeholders in education likewise raise accusing finger of low academic achievement to lack of interest by students in secondary schools in Enugu State [2]. Others attribute the low performance of students to lack of motivation and readiness to learn. In a similar way, some are of the opinion that students find it difficult to sit down and study their books owing to inclination to distractions and less concentration in their studies [3]. On that same note, the researchers observed some complex habits among students in form of academic procrastination which hinder their academic achievement especially in core subjects like mathematics.

One thing is to identify a problem and another is to proffer solution to the problem. Therefore, with this habit of procrastination among students as identified by the researchers, educators are challenged within their areas of practice on which sound intervention approaches to apply on this sabotaging habit and behaviour that hinder students from achieving to their full potential. This sabotaging behaviour of procrastination is what most students have indulged in, in one way or the other (Klein, cited in [4]). Unfortunately, it is noted that no matter how efficient or committed an individual is, there are likelihood that he or she must have been found throwing away time on insignificant things instead of spending that time on school-related tasks. Although this is an observed 
fact that most students have procrastinated sometimes in their cause of study but this study is mostly concerned with those students who have become habitual procrastinators because procrastination is regarded as negative only if the tendency becomes habitual, addictive and thus resulting to low academic achievement among those students who indulge in it as most of them are experiencing today.

From all indications, academic procrastination starting from the researchers' observations, to existing literature and even from its definition, is portrayed as bad and negative in nature. Most often, academic procrastination consists of the intentional delay of an intended course of action, in spite of an awareness of negative outcomes [4,5]. From a simple explanation, procrastination is the act of putting off tomorrow what should be done today. More still, one should not use procrastination inter-changeably with the word delay since it is different from delay because delay has rational reasons behind putting-off something as opposed to procrastination [6]. This practice can have unfortunate effects on an individual if he or she makes a habit of it or indulges in it repeatedly. Procrastination is the delaying of a task that was originally planned despite expecting to be worse off for the delay [7]. All the definitions of procrastination have common theme revealing a core or essential element. It is evident that all conceptualizations of procrastination recognize that there must be a postponing, delaying, or putting off of a task or decision, which is in line with Latin origin of procrastination, pro, meaning forward, forth, or in favour of, and crastinus, meaning of tomorrow (Klein, cited in [4]). Thus, it is very obvious that academic procrastination is irrational but students end up voluntarily choosing a course of action that they know will not maximize their physical, psychological, mental wellbeing and their goals in life.

The repercussion of procrastination is very miserable indeed as it has been found that the more an individual finds a particular task as difficult and hard, the more that individual procrastinate over that task. Mathematics is one of the academic tasks that most students complain about and it is tagged as being difficult. This is a big problem both now and in future since mathematics which stands as a life wire of scientific and technological development is mostly avoided by so many low achieving students. It has been observed that some students just avoid mathematics because they do not like figures. This avoidance may not be as a result of their ability but many students refer to mathematics as difficult. As noted by some researchers, when a task seems difficult, unpleasant, or overpowering, it may bring about procrastination [8,9] which remains one of the least understood human miseries [10]. Procrastination is considered bad, irrational way of thinking and as a consequence, produces inefficient and maladaptive behaviour. Therefore, in order to avert the situation of the disrupting, self-defeating chain of thought, feeling and academic procrastination which translates to low academic achievement especially in mathematics among students, selected psychotherapeutic interventions are required and most effective in this case should be Cognitive Behaviour Therapy (CBT) and Solution-Focused Brief Therapy (SFBT). Cognitive Behaviour Therapy (CBT) is an insight-focused therapy that emphasizes, recognizes and changes negative thoughts and maladaptive beliefs in individual [11]. CBT was originally developed by Aaron T. Beck, for depression but has been used to improve other behavioural cases [12]. The premise of cognitive behaviour therapy is that our thoughts influence our feelings and behaviour. Beck theorized that by changing our thoughts or our relationship to our thoughts; we can change behaviour and emotion [11]. Furthermore, CBT approach is based on the theoretical rationale that the way people feel and behave is determined by how they perceive and structure their experience [11].

Cognitive Behaviour Therapy (CBT) has two components, the cognitive and behavioural components. The cognitive helps people change thinking patterns that keep them from overcoming their fears through cognitive restructuring. For example, a person with habit of procrastination will be helped to see that his or her task avoidance attitude due to fear of tackling the problem at hand as previously fared can be overcome. The behavioural component of CBT seeks to change people's reactions to anxiety-provoking situations. A key element of this component here is exposure, in which people confront the things they fear and start to take action instead of procrastinating. CBT proposes that change comes about by changing the client's thinking about the situation. Once the client has converted his or her point of view, the problem-perception switches to a clearer context [12].

Solution Focused Brief Therapy (SFBT) can also be used to challenge the situation of these disrupting selfdefeating chain of thought, feeling and academic procrastination which translates to low academic achievement especially in mathematics among students. It is a new and increasingly used therapeutic approach that focuses on helping clients construct solutions rather than solve problems [13]. Solution-focused brief therapy was developed for over 20 years by Steve de Shazer, and Insoo Kim Berg, and has been used in variety of contexts including schools agencies and private practice, with a wide range of clients including children, adolescents, couples, families (Reiter, cited in [14]). In SFBT, life is imagined as a pie chart, with each slice of the pie a different size [15]. At any given time, some sections of the pie are going to be off or not functioning at its best and that is normal. A client who is problem-focused is looking only at this one slice of the pie that is not functioning. A solution-focused therapist is going to help the client fix that slice by balancing strengths that are part of the rest of the pie and that is how the therapy works. Academic achievement becomes that part of the pie that is not functioning well in the life of the student due to habitual procrastination which needs to be fixed.

This remains a big challenge to educationists and requires urgent intervention to improve the present situation. The consequence is that if students do not get help, they progressively deepen their disturbance and end up in a state of hopelessness in which they relinquish efforts to change or improve their circumstances. Mathematics as a foundation for scientific and technological advancement is mostly affected when it comes to task avoidance. That is why there is continues students' low achievement in mathematics both in internal and external examinations in Enugu State [2]. 
Mathematics holds the key to national development, yet it is observed that the same mathematics has one of the highest failure rates in all public examinations right from common entrance examination into Junior Secondary School, to Senior School Certificate Examination (SSCE), and National Examination Council (NECO) examination [16]. Furthermore, external examination result as shown in May/June 2014 WASSCE indicates that 70 percent of candidates who took the examination failed to obtain credits in Mathematics [1]. This shows an obvious need of effective interventions to restructure students' mind since they believe that mathematics is difficult to understand and leads them to procrastinate.

In conclusion, the researchers believe that, if students are given the opportunity to experience mathematics aesthetically during mathematics lessons in addition with the selected psychotherapeutic intervention, their interest will be aroused, stimulated and kindled in studying mathematics and in solving mathematics problems. That was exactly the case as the interest which this approach generated led to students working harder, spending more time and energy solving mathematics problem and their academic tasks in general since people spend more time in things that interest them. As students reduce procrastinating, their interest in academic tasks is sustained, definitely mathematics phobia and sense of difficulty in mathematics vanishes leading to greater positive improved mathematics achievement in Enugu State. It was in an effort to solve the problem of low academic achievement of students in mathematics that this study was carried out and in so doing the researchers have contributed to the frontier of knowledge.

This study was guided by two research questions and two corresponding hypotheses thus:

1. What are the differential effects of the two independent variables, CBT and SFBT on procrastination reduction among low achieving students in the experimental groups based on their post-test scores on the Procrastination Assessment Scale-Student (PASS)?

2. What is the difference in mathematics improvement of the low achieving students in CBT and SFBT experimental groups and control group based on their teacher made mathematics achievement test (TMMAT) post test scores?

3. There is no significant differential effects of the two independent variables, CBT and SFBT on procrastination reduction among low achieving students in the experimental groups based on their pre-test post-test score on the PASS.

4. There is no significant difference in mathematics improvement of the low achieving students of CBT and SFBT experimental groups on their mathematics achievement test pre-test and post test scores.

\section{Methodology}

This study adopted quasi-experimental, pre-test, post-test, control group, research design. The three-group quasi-experimental design was most suitable for the study which consists of two independent variables (Cognitive Behaviour Therapy and Solution-Focused Brief Therapy) and two dependent variables (low achieving students' procrastination reduction and mathematics improvement). In notational form, three-group quasi-experimental design is as illustrated in Figure 1 having two experimental groups and one control group.

\begin{tabular}{clccc}
\hline Groups & Types of treatment & Pre-test & Treatment & Post-test \\
\hline 1 & CBT & $0_{1}$ & $\mathrm{X}_{1}$ & $0_{2}$ \\
2 & SFBT & $0_{3}$ & $\mathrm{X}_{2}$ & $0_{4}$ \\
3 & CONTROL & $0_{5}$ & & $0_{6}$ \\
\hline
\end{tabular}

Pre-test $\left(0_{1}, 0_{3}, 0_{5}\right)$; Treatment $(\mathrm{X} 1, \mathrm{X} 2)$; Post-test $\left(0_{2}, 0_{4}, 0_{6}\right)$.

Figure 1. Illustration of three-groups quasi-experimental design.

The population for this study consisted of all 160 procrastinating and low achieving students (male and female) in SS1 classes of three secondary schools in urban area in Enugu North of Enugu State. The three secondary schools are Government Secondary School Enugu, New Layout Secondary School and Coal Camp Secondary School.

A purposive sampling technique was applied to draw a sample of 36 participants from Government Secondary School, New Layout Secondary School and Coal Camp Secondary School in Enugu North, Enugu State, Nigeria. The treatment of the two experimental groups (CBT and SFBT) lasted for 15 weeks of 55 minutes per session per week for each of the two groups. Group I was treated with CBT while group 2 was treated with SFBT. None of these treatments was given to the control group.

The instruments used for data collection include the following: Procrastination Assessment Scale-Student (PASS), Teacher Made Mathematics Diagnostic Test (TMMDT) and Teacher Made Mathematics Achievement Test (TMMAT). Procrastination Assessment ScaleStudent (PASS) was adapted from original procrastination scale developed and validated by Solomon and Rothblum (1984). The researchers decided to modify the instrument to adapt it to the characteristics of the target group. Out of 44 items from the original PASS, 30 items were adapted and modified to be used as instrument for data collection in this study. The PASS is a five point Likert scale, with the following response options and corresponding weights - Always = 5, Nearly Always =4, Sometimes =3, Almost Never $=2$, Never $=1$. Score 30 stands for an occasional procrastinator; $31-50$ is a chronic procrastinator, while above 50 is a severe procrastinator - the higher the score, the higher the level of procrastination (Adapted from [17]). The Teacher Made Mathematics Diagnostic Test (TMMDT) was used as a take-off assessment which was based on the students' first term scheme of work made of 20 objective questions, to be answered in 30 minutes. The TMMDT was used as a confirmation of low achievement in mathematics. Teacher made mathematics diagnostic test (TMMDT) was administered to the three groups before the treatment while the teacher made mathematics achievement test (TMMAT) was administered to the three groups as pre-test and post-test. The teacher made mathematics achievement test (TMMAT) was based on the students' second term scheme of work made of 20 objective questions and 5 theory questions which were answered in 1 hour 30 minutes.

In order to establish the reliability of the instruments, (Procrastination Assessment Scale for Students (PASS), the Teacher Made Mathematics Diagnostic Test (TMMDT) 
and the Teacher Made Mathematics Achievement Test (TMMAT), a pilot study was carried out on a sample of six (6) low achieving students of Community Secondary School Eva Valley still in Enugu North L.G.A in Enugu State. Test Retest method whereby same test was given to the same group of subjects on two separate occasions of two weeks interval to avoid memory effect was adopted in ascertaining the reliability co-efficient of the instruments. The reliability co-efficient, using Pearson's product moment correlation method was PASS $=.900$, TMMDT $=$ 0.816 , TMMAT $=0.868, \mathrm{~N}=6$ respectively. With the obtained coefficients, the researchers deemed the three instruments suitable to be used for the study.

\section{Results}

Results of statistical analysis of the research questions and hypotheses are presented in the following tables.

Table 1. Mean and standard deviation analysis of differential effects of CBT and SFBT on academic procrastination reduction

\begin{tabular}{lcccc}
\hline Groups & $\begin{array}{c}\text { Mean } \\
(\bar{X})\end{array}$ & $\mathrm{N}$ & Std. Deviation & $\begin{array}{c}\text { Std. Error } \\
\text { Mean }\end{array}$ \\
\hline 1CBT Pre-test & 66.4167 & 12 & 4.03301 & 1.16423 \\
Post-test & 37.00 & & 3.46410 & 1.00000 \\
2 SFBT Pre-test & 66.2500 & 12 & 4.09268 & 1.18145 \\
Post-test & 34.6667 & & 4.20678 & 1.21439 \\
3 Control Pre-test & 65.9167 & 12 & 3.91868 & 1.13123 \\
Post-test & 66.1667 & & 3.95045 & 1.14040 \\
\hline
\end{tabular}

Table 1 shows that the CBT group had post-test mean score ( $\bar{X}=37.0000)$ which is lower than their pre-test mean score ( $\bar{X}=66.4167)$ on PASS. This result revealed that there was a reduction in the post-test scores after the students' treatment with CBT. Also, the result for SFBT group from PASS shows that the post-test mean score ( $\bar{X}=34.6667$ ) is lower than their pre-test mean score ( $\bar{X}=66.25000$ ). This result was an indication that SFBT caused procrastination reduction in their post-test score. Furthermore, the result from the Control group from PASS shows that the post-test mean score ( $\bar{X}=66.1667$ ) is the same when compared with pre-test mean scores ( $\bar{X}=65.9167$ ). When comparing the mean scores from the three groups, those in SFBT showed a higher procrastination reduction, followed by CBT group, while the control group who had no psychotherapeutic intervention experienced no procrastination reduction. Again for CBT group, their $\mathrm{SD}$ value on procrastination reduction (3.46410) for the post-test suggest that the responses or the scores of the respondents between the pre-test and post-test are widely spread. The SD value of SFBT group on their procrastination reduction is 4.20678 for the post-test. This suggests that the responses or the scores of the respondents between the pre-test and post-test are widely spread from the mean even more than those in CBT. On the other hand the SD of the Control group on their post-test (3.95045) and pre-test (3.91868) are very close.
Table 2. Mean and S.D analysis of difference in mathematics improvement of the low achieving students of the experimental groups and control group due to CBT and SFBT

\begin{tabular}{ccccc}
\hline Groups & $\mathrm{N}$ & Mean $(\bar{X})$ & Std. Deviation & $\begin{array}{c}\text { Std. Error } \\
\text { Mean }\end{array}$ \\
\hline Exp. CBT & 12 & 51.2500 & 6.44029 & 1.85915 \\
Exp. SFBT & 12 & 52.9167 & 6.20056 & 1.78995 \\
Control Group & 12 & 39.1667 & 3.58870 & 1.03597 \\
\hline
\end{tabular}

The result on Table 2 shows that students in CBT had post-test mean score of 51.25 and standard deviation value of 6.44. Students in SFBT had post-test mean score of 52.91 and standard deviation value of 6.20. Students in Control group had post-test mean score of 39.27 and standard deviation value of 3.59. The individual responses in mathematics improvement of students in CBT and SFBT widely deviated from the mean more than those in Control group.

Table 3. ANOVA showing the differential effect of procrastination reduction among the three groups

\begin{tabular}{cccccc}
\hline $\begin{array}{c}\text { Source of } \\
\text { variance }\end{array}$ & df & SS & MS & F & P \\
\hline Between Group & 2 & 7393.556 & 3696.778 & 244.803 & 0.001 \\
Within Group & 33 & 498.333 & 15.101 & & \\
Total & 35 & 7891.889 & & 3.58870 & 1.03597
\end{tabular}

Table 3 reveals that in between groups, the sum of square is 7393.556 with 2 degree of freedom and a means square 3696.778 for within groups, the sum of square is 498.33 and 33 degree of freedom as well as a mean score of 15.101 . The total has 7891.89 sum of square and 35 degree of freedom. The computed $F$ is 244.80 which is statistically significant even as at low as .001 alpha. Therefore, the hypothesis that says that "there is no differential effects of the two independent variables, (CBT and SFBT) on procrastination reduction among low achieving students in the experimental groups based on their post-test scores” is rejected, $\mathrm{F}(2,33)=244.80, \mathrm{p}<.001$.

Table 4. ANCOVA showing improved mathematics achievement in the experimental groups (CBT and SFBT) but no improvement in the control group

\begin{tabular}{cccccc}
\hline $\begin{array}{c}\text { Source of } \\
\text { variance }\end{array}$ & $\begin{array}{c}\text { Sum of } \\
\text { squares }\end{array}$ & df & $\begin{array}{c}\text { Mean } \\
\text { square }\end{array}$ & F & Sign \\
\hline $\begin{array}{c}\text { Variance } \\
\text { controlled } \\
\text { (Pre-test scores) }\end{array}$ & 351.33 & 1 & 351.33 & 16.79 & 0.00 \\
Intercept & 66.68 & 1 & 66.68 & 3.19 & 0.08 \\
Main effect & 1399.20 & 2 & 699.60 & 33.44 & 0.00 \\
Error & 669.51 & 32 & 20.92 & & \\
Total & 2372.22 & 36 & & & \\
\hline
\end{tabular}

The result in Table 4 shows that $F(2,32)=33.44, p=001$. Between groups are presented in main effect (VAR00003) rows while within groups is presented in Error rows. In main effect rows, Type III sum of square is 1399.20, degree of freedom, mean square 699.60, $2 \mathrm{~F}$ ratio and $\mathrm{p}=.001$ significance. The Error has type sum of square of 669.51, degree of freedom of 32 and mean square of 20.92. 
The computed ANCOVA coefficient $(F)$ is $16.79, \mathrm{p}<.001$ and is statistically significant at possible chosen alpha level of .05 with its actual probability in the population is as low as .001. Therefore, with the effect of the Pre-test covaried out, adjusted for, removed or partialled out, the hypothesis which states that "there is no significant difference in mathematics improvement of the low achieving students of CBT and SFBT experimental groups on their mathematics achievement test pre-test and posttest scores" is rejected both at .05 and .01 levels of significance. There is statistically significant mean difference among the experimental groups and control group because $\mathrm{F}(2,32)=, \mathrm{p}<.05$.

\section{Discussion of Results}

The results from the findings reveal that null hypothesis 1 is rejected. Table 3 shows that in between groups, the sum of square is 7393.556 with 2 degree of freedom and a means square of 3696.778 for within groups; the sum of square is 498.34 and 33 degree of freedom as well as a mean square of 15.101 . The total has 7891.89 sum of square and 35 degree of freedom. The computed $\mathrm{F}$ is 244.80 which is statistically significant even as at low as .001 alpha. Therefore, the hypothesis is rejected, $\mathrm{F}(2,33)=244.80, \mathrm{p}<.001$. From this finding, one can say that although CBT and SFBT are effective in academic procrastination reduction, students seem to be more comfortable with SFBT and that yielded more result. In line with this observation, Bloom and Tam [18], illustrated that models of Cognitive Behaviour Therapy (CBT) and Solution-Focused Brief Therapy (SFBT) differ in their primary focus: problem solving versus solution building. These theoretical differences they noted leads to dissimilar practices, including the content of the therapeutic dialogue. Specifically, CBT sessions include more talk about negative topics in clients' lives such as problems and situational difficulties, whereas SFBT sessions focus on positive topics in clients' lives such as strengths and resources. This differential result may be attributed to the fact that people perform better when one build on their strength than when one emphasis their deficiencies.

Furthermore, in the same view Jordan, Froerer, and Bavelas [19] added that CBT and SFBT therapists make different assumptions about their clients. CBT therapists view clients as having unhealthy or faulty cognitions that lead to problematic behaviours. SFBT therapists assume that clients possess all of the resources they need, so there is no need to identify deficiencies or pathologies. Such contrasting assumptions affect the delivery of therapy in important ways.

Another reason for the effects of SFBT in this study might be as a result of language as it is in line with De Jong, Bavelas, and Korman, [20] who observed that there are differences in CBT and SFBT in terms of their assumptions about the role of language in psychotherapy. CBT therapists ask questions in order to gather more information about problematic thoughts and behaviours in order to change faulty thinking. SFBT therapists ask questions to introduce new possibilities and co-construct new meanings. In this view, therapists and clients are not simply sending information about the client back and forth to each other. Their dialogue is actively shaping a new version of the client's life. Students are not comfortable when you talk about their inability but are more motivated when you talk about their ability and strength.

From the findings of this study SFBT has shown to be effective and that has supported the claim of Franklin, Moore and Hopson [21] in their study which evaluated the effectiveness of Solution-Focused Brief Therapy on children who have classroom-related behaviour problems within a school setting. In their study of five to seven sessions of Solution-Focused Brief Therapy, services were provided to 67 children, who were identified by school faculty and staff as needing assistance in solving behaviour problems. Outcomes were evaluated by using a pre-test/post-test follow-up design with a comparison group. Effect sizes and improved percentage scores were calculated. Findings provide support that SolutionFocused Brief Therapy was effective in improving, internalizing and externalizing behaviour problems.

The ANCOVA result in Table 4 which was used to test hypothesis 2 shows that $\mathrm{F}(2,32)=33.44, \mathrm{p}=001$. In main effect rows, type III sum of Square 1399.20 degree of freedom, mean square $699.60,2 \mathrm{~F}$ ratio and $\mathrm{p}<.001$ significance. The error has type sum of square of 669.51, degree of freedom of 32 and mean square of 20.92. The computed ANCOVA coefficient (F) is 16.79, $\mathrm{p}<.001$ which is statistically significant at possible chosen alpha level of .05 with its actual probability in the population is as low as .001. In this case there is statistically significant means difference among the experimental groups and control group because $\mathrm{F}(2,32)=, \mathrm{p}<.05$. There was real improvement of the students' in the two experimental groups having a significant improvement after the therapeutic interventions. This shows that some psychotherapeutic interventions improve low academic achievements especially in mathematics.

This finding is line with Oundo, Nyaga, Barchok, and Mureithi [22] who carried out a study to assess counselling needs related to mathematics performance among secondary school students in Maara District in Kenya. The study examined counselling needs regarding attitudes, study methods and test taking skills related to mathematics performance and determined whether statistically significant differences existed between psychological intervention requirements and mathematics counselling needs among the secondary school students. The study findings indicated that secondary school students had mathematics counselling needs in relation to attitude, study methods and test taking skills for which psychological intervention was necessary. The data analysis results indicated that $53.3 \%$ of student participants were female while $46.7 \%$ were male. Their age ranged between 16 years and 20 years with the majority comprising $48.9 \%$ being 17 years old. The students' mathematics performance at the primary level examinations was fair with the majority constituting $53.9 \%$ scoring above the average grade compared to only $10.4 \%$ at secondary level examinations. This implies that there exist factors limiting students' performance in mathematics at secondary school examinations and therefore, interventions may mean progress in mathematics achievement for the students. 
From the findings in this study one can deduce a link with the significant academic procrastination reduction as is seen in Table 4 with improved mathematics achievement. This is in agreement with the study carried out by Akinsola, Tella, and Tella [23], where they examined the correlates between academic procrastination and mathematics achievement among the university mathematics undergraduate students. The study used a total sample of 150 part 3 and 4 students in The Department of Mathematics and Mathematics Education in The University of Ibadan and University of Lagos, Nigeria. The 35 items academic procrastination scale developed and validated by Tuckman [24] was used for the collection of data in conjunction with the subjects GPA scores till date in mathematics. Findings indicate that a significant correlation was found in the academic procrastination and academic achievement of the subjects in mathematics, significant difference also exists in the levels of procrastination and mathematics achievement of the subjects, with low procrastinators performing better than the moderate and the high procrastinators. That is to say that while the control could not improve in their mathematics achievement was because they are high procrastinators. Still in another study by Akinsola and Tella [23] in The Department of Mathematics and Mathematics Education of The University of Ibadan and University of Lagos, they found that the more the subjects procrastinate, the more their achievement in mathematics decreased. This goes to explain why those in control group performed poorly.

\section{Conclusion}

From the findings of this study titled: Differential-effect of selected psychotherapeutic intervention on academic procrastination reduction and improved mathematics achievement among low achieving students, the researchers' then conclude that:

- There is a differential significant effect of the two independent variables, CBT and SFBT on procrastination reduction among low achieving students although SFBT group achieved better results.

- Both psychotherapeutic intervention CBT and SFBT had significant difference in mathematics improvement among low achieving students.

From the results of the findings of the study both CBT and SFBT are effective psychotherapeutic interventions that can reduce academic procrastination and improve mathematics achievement among low achieving students in secondary schools although SFBT has proved to be more effective in this case.

\section{Recommendations}

Eight recommendations come to mind in the light of the results of this study. They are as follows:

1. Counselling and psychotherapy should be taken very serious in various levels of education in Enugu State and Nigeria in general as a tool to bring back the glory of academic achievement.
2. Counsellors in the secondary schools should not be given any teaching subject rather they should concentrate in providing their professional counselling services.

3. Teachers in the secondary schools should collaborate with their guidance counsellors in order to help the students achieve their full potentials.

4. Mathematics teachers in the secondary schools should learn to build on students' strength instead of labelling some students as never do well in mathematics. With little encouragement even those who avoid mathematics can turn to be average students in the subject.

5. Counsellors should be involved in constant research and seminars or workshops in order to be current on the best way to help students in their learning processes.

6. The government has a great role to play in motivating counsellors and teachers to carry out their work diligently by paying them good salary and when due. In-service training for teachers and counsellors can also serve as a motivational tool for them to grow in their profession.

7. Very important still, is for government to always provide enabling environment for teaching and learning. Students learn better in good environment and when motivated. Mathematics text books should carry some illustrations and pictures to attract the attention of low achieving students in the subject.

8. Students should be helped to achieve their educational goals. This implies that there exist factors limiting students' performance in mathematics at secondary school examinations and therefore, interventions may mean progress in mathematics achievement for the students.

\section{References}

[1] Folarin, F. (2014). Poor WAEC Results: Fallout of Falling Education Standards? Retrieved from:

http://dailyindepentnig.com/2014/08/poor-waec-results-falloutfalling-education-standards.

[2] Ekundayo, H.T. (2010). Administering secondary schools in Nigeria for quality output in the $21^{\text {st }}$ century: the principals' challenge. European Journal of Educational Studies. 2(3), 187-190.

[3] Anugwara, B. (2013). Reviving reading culture among youths, Enugu speaker's example. Retrieved from: http://www.mydailynewswatchng.com/reviving-reading-cultureamong-youths-enugu-speakers-example/?Wpmp witcher-mobile.

[4] Steep, P. (2007). The nature of procrastination: a meta-analytic and theoretical review of quintessential self-regulatory failure. Psychological Bulletin 133(1), 65-94.

[5] Chow, H.P.H. (2011). Research note on procrastination among undergraduate students: effects of emotional intelligence, school life, self-evaluation, and self efficacy.

[6] Steel, P. (2011). The procrastination equation: how to stop putting things off and start getting things done. Murdoch Booms Pty Limited.

[7] Van-Eerde, W. (2003). A meta-analytically derived homological network of procrastination. Personality and Individual Differences, 35, 1401-1418.

[8] Erden, M. \& Akgul, S. (2010). Predictive power of math anxiety and perceived social support from teacher for primary students mathematics achievement. Journal of Theory and Practice in Education, 6(1), 3-16. 
[9] Asikhia, A. (2010). Academic procrastination in mathematics: causes, dangers and implications of counselling for effective learning. International Education Studies, 3, (3), 205-210.

[10] Karatas, H. (2015). Correlation among academic procrastination, personality traits, and academic achievement. Anthropologist, 20(1,2), 243-255.

[11] McFarr, L.M. (2013). An update on CBT training guidelines for doctoral programs. Advances in Cognitive Therapy, 14(1), 9-12.

[12] Hofmann, S.G. (2011). An introduction to modern CBT. Psychological Solutions to Mental Health Problems. Chichester, UK: Wiley-Blackwell.

[13] Gingerich, J.G. \& Eisengart, S.M. (2000). Solution-Focused Briefly Therapy: review of the outcome research. Family Process, 39, (4), 477-498.

[14] Lightfoot, J.M. (2014). Solution-Focused Brief Therapy International Journal of Scientific and Engineering Research, $5(12)$.

[15] Newsome, W. (2015). The impact of Solution-Focused Briefly Therapy with at-risk junior high school students. Children and Schools, 27, 83-90.

[16] Kurumeh, I.M.S. \& Chiawa, M.A. (2009). Improving students' interest in solving algebraic word problems using aesthetic value approach research. Journal of Mathematics and Statistics 1(2), 59-64.

[17] Solomon, L.J., \& Rothblum, E.D. (1984). Academic procrastination: frequency and cognitive-behavioural correlates. Journal of Counselling Psychology, 31, 503-509.
[18] Bloom, K. \& Tam, J.A. (2015). Walk-in services for child and family mental health. Journal of Systemic Therapies 34(1), 61-77.

[19] Jordan, S.S., Froerer, A.S., \& Bavelas, J.B. (2013). Microanalysis of positive and negative content in solution-focused brief therapy and cognitive behavioural therapy expert sessions. Journal of Systemic Therapies, 32(2), 46-59.

[20] De Jong, P.; Bavelas, J.B. \& Korman, H. (2013). An introduction to using microanalysis to observe co-construction in psychotherapy. Journal of Systemic Therapies 32(3), 17-30.

[21] Franklin, C. Moore, K., \& Hopson, L. (2008). Effectiveness of Solution-Focused Briefly Therapy in a school setting. Children and Schools, 30, 15-26.

[22] Oundo, M.B., Nyaga, V.K., Barchok, H.K. \& Mureithi, M.M. (2013). Assessment of counselling needs related to mathematics performance among secondary school students in Maara District, Kenya. American International Journal of Contemporary Research, 3, $8-20$.

[23] Akinsola, M.A. \& Tella, A. (2007). Correlates of academic procrastination and mathematics achievement of university undergraduate students. Eurasia Journal of Mathematics, Science and Technology Education, 3(4), 363-370.

[24] Tuckman, B.W.; Abry, D.A. \& Smith, D.R. (2000). Learning and motivation strategies: your guide to success. Upper Saddle River, N.J: Prentice-Hall. 